\title{
Enriching Learners' Vocabulary by Means of Derivative Word-Building Patterns
}

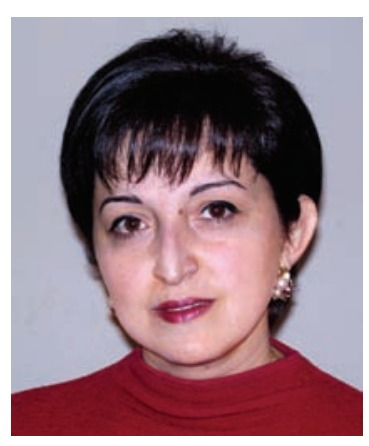

Lili Karapetyan

$\mathrm{Z}_{1500 \text { years of development. It has been estimated }}^{\text {nglish vocabulary has increased greatly in more than }}$ that the present English vocabulary consists of more than one million words, including slang and dialectal expressions, scientific and technical terms, many of which only came into use after the middle of the $20^{\text {th }}$ century. Thus, the English language has one of the most extensive vocabularies in the world. However, the average native speaker uses around only five thousand words in everyday speech.

Extensive, constant borrowings from major languages, especially from Latin, Greek, French, the Scandinavian languages, and from numerous minor languages, account for the great number of words in the English vocabulary. In addition, certain processes have led to the creation of many new words, as well as to the establishment of patterns for further extension. Among these processes are affixation, compounding and conversion, which are the three main types of word-formation characteristic of the English language. Since there are few established rules of compounding and conversion, it would be reasonable to focus on affixation, which is probably the most important of the above mentioned processes and appears to have added the largest number of words to the English vocabulary.

Suffixes continue to be productive in the formation of many new words in English. For example, -iac has been added to the word brain to create the new word brainiac (someone who spends a lot of time studying and thinking about complicated ideas, but who is often unable to communicate with people in ordinary social situations). A large number of new words have also been created through the addition of the suffix -ization, as in dollarization (a situation in which countries outside the US want to use the dollar rather than their own country's currency) or globalization (the process by which countries all over the world become connected, especially because large companies are doing business in many different countries).

Prefixes have become more widespread recently. Cyber- is a good example of prefix which has been used to create a range of new words (originally meaning "computer", now often meaning "to do with the Internet") cybercrime, cyberfraud, cyberland. Dozens of new words formed by prefixes relate to size, both large and very small, such as micro-, super- and multi-, as in microbrewery (a small company that makes only small quantities of beer), microengineering, supersize, multi-tasking. 
The vast majority of the new words entering the language are made up out of existing components.

In the context of learning English as a foreign language, a good syllabus could do a lot to heighten learners' awareness of high-frequency patterns of affixation in English. To teach learners strategies, to help them cope with the language that is new to them, R. Gairns and S. Redman (2001) suggest a variety of different classroom activities which focus on different aspects of word-building. They point out that the time and effort devoted to this area in the classroom will depend on the teaching situation, the needs and goals of learners.

It must also be mentioned that learners' ideas of the word-building possibilities of the target language are strictly influenced by their native language. For speakers of Latin-based languages, certain prefixes and suffixes in the English language will be similar to those of their mother tongue and, therefore, will present little difficulty. Meanwhile Armenian speakers will have difficulties in learning these affixes since Armenian and English have different morphological systems.

Learners also need to be autonomous and independent and to make conscious efforts to learn vocabulary outside the classroom because the exposure to the target language is limited in class. So, explicit vocabulary teaching is necessary for learners to be able to guess the meaning of some unknown words without a dictionary and also to make up some potential words - words which do not exist but which could conceivably become part of the language.

This aim can be achieved through word-building patterns, by which we understand a 'fixed structure which has a generalized word-building meaning and can be filled with various material' (Степанова, 1968). And by word-building meaning we understand the meaning of the derived word, which is inferred from the meanings of the structural components of the pattern.

Inference to a great extent depends on the correspondence of the structures of the foreign language to those of learners' native tongue. If the structural and semantic relations existing between the affix and the base coincide, or if a regular correspondence can be established between them, the degree of inference of the words built on that pattern becomes considerably high.

According to this principle, such word-building patterns as "un- + Adj" (unpleasant), " $N+$-less" (useless), “Adj + -ness" (darkness), "Adj + -y”(cloudy), etc. can be selected for teaching purposes, while patterns like " $N+$-esque" (arabesque), "Adj +-some" (wholesome) and the like cannot as in the first case the semantic relations between the elements are clear, while in the latter case they are not.

The clearer the word-building pattern, the freer the formation of new words analogous to it will be.

Derivative word-building patterns will help to develop language learners' receptive and reproductive skills. With receptive skills learners will be able to make informed guesses about the meaning of unknown units; in terms of reproductive skills a knowledge of some productive word-building patterns will widen learners' creative abilities, which can also be treated as a communicative strategy. 
For teaching purposes we give preference to developing receptive skills for learning word-building patterns since the possibilities of word-creation are limited in every language. In this respect, learners need to acquire receptive skills to enable them to understand the meanings of unknown words while reading texts. In fact, studies show that skilled readers fill in sentence blanks with the morphologically correct words, regardless of whether the word choices are real or nonsense words. They are able to respond to the components of the patterns themselves and not just to familiar words. Not only does this strategy help learners read more words quickly, it also helps them distinguish between true morphological relationships (such as, 'space/spacial') and false ones (like 'tail/tailor'), which, in turn, speeds reading efficiency.

The ability to infer the meaning of a derived word leads to the extension of learners' potential vocabulary and the development of grounded linguistic guesswork.

As Bright and McGregor (1970: 31) point out: "Perhaps the most important thing of all is to remember that the ability to infer in this way is a skill that can only be acquired by practice. Every time we tell a pupil what a word means, we are robbing him of a chance to practise that skill".

Nation, however, argues that using affixation and roots alone as a means of guessing is unreliable, and states that, if it is used as an initial step in the guessing process, this guess at the meaning is more likely to lead to twisting the interpretation of the context than allowing interpretation of the context to modify the guess at the meaning. In other words, when learners make an incorrect guess based on word form, they try to interpret the context to support the incorrect guess. Indeed, the same derivative word can have different meanings, and it is the context that determines the right meaning. Thus, in the sentences
1. He has foxy lips.
2. He is a foxy guy.
3. He has foxy hair.

the adjective foxy has quite different meanings 1 . similar to an animal, 2. similar to a man possessing some qualities of that animal, 3. a definite colour - reddish-brown .

As has already been stated above, word-building patterns can be looked upon as a resource in the language, something the learners should be allowed to experiment with and use strategically. Isolating a small group of highly productive word-building patterns, we might observe, for example, whether they can encourage learners to create new words. Some of their creations will probably be words that already exist in the language, others will be non-established words. This latter group need not be ignored, but can be explored for literary value or simply for filling 'gaps' in the language. Creative word-formation can also be seen as a communicative strategy, for supplying formations when the right word cannot be found.

Thus, the better a foreign language learner masters the word-building structures of the language, the wider his possibilities of assimilating the vocabulary are. 


\section{References:}

1. Степанова М.Д. Методы Синхронного Анализа Лексики. М., 1968.

2. Bright J.A., McGregor G.P. Teaching English as a Second Language. London, 1970.

3. Nation P. Learning Vocabulary in Another Language. Cambridge: Cambridge University Press, 2001.

4. Gairns R., Redman S. Working with Words (A Guide to Teaching and Learning Vocabulary). Cambridge: Cambridge University Press, 2001.

5. McCarthy M. Vocabulary. Oxford: Oxford University Press, 2001.

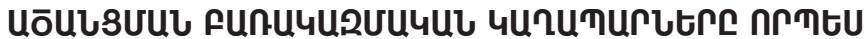

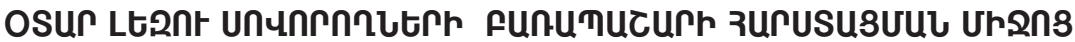

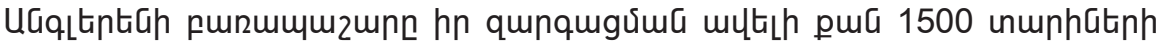

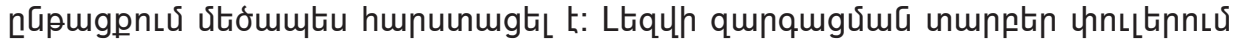

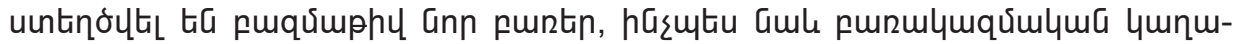

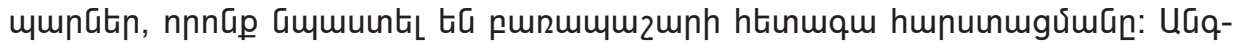

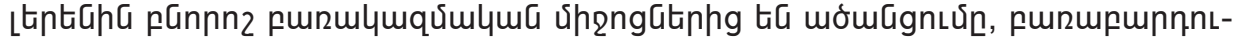
un le uhntumlumpnspjnıGn:

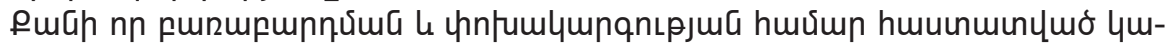

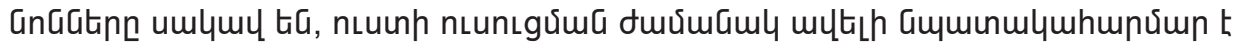

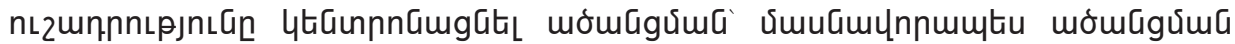

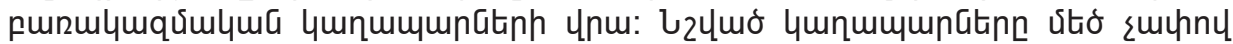

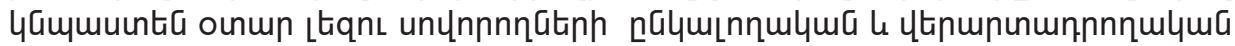

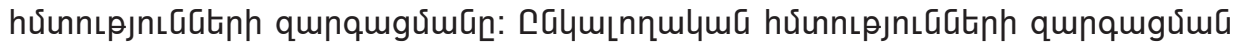

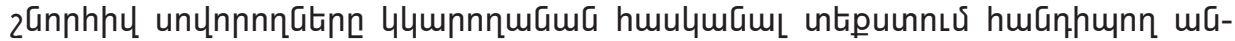

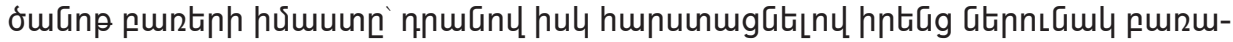

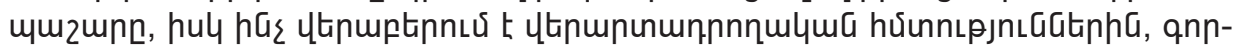

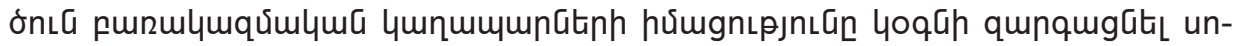

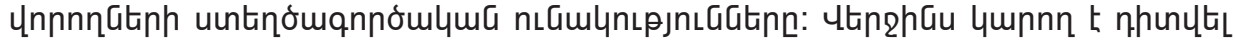

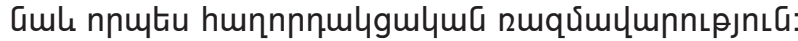

